\title{
Influences of wind-wave exposure on the distribution and density of recruit reef fishes at Kure and Pearl and Hermes Atolls, Northwestern Hawaiian Islands
}

\author{
Edward E. DeMartini • Brian J. Zgliczynski • \\ Raymond C. Boland·Alan M. Friedlander
}

Received: 25 November 2008 / Accepted: 14 July 2009 / Published online: 25 July 2009

C The Author(s) 2009. This article is published with open access at Springerlink.com

\begin{abstract}
This paper describes the results of a field survey designed to test the prediction that the density of benthic juveniles of shallow-reef fishes is greater on wind-wave "exposed" sectors of a pair of isolated oceanic atolls (Kure, Pearl and Hermes) at the far
\end{abstract}

Electronic supplementary material The online version of this article (doi:10.1007/s10641-009-9514-3) contains

supplementary material, which is available to authorized users.

E. E. DeMartini $(\bowtie)$

NOAA Fisheries, Pacific Islands Fisheries Science Center, Aiea Heights Research Facility,

99-193 Aiea Heights Drive,

Aiea, HI 96701-3911, USA

e-mail: edward.demartini@noaa.gov

\section{B. J. Zgliczynski}

Center for Marine Biodiversity and Conservation,

Scripps Institution of Oceanography,

University of California, San Diego,

9500 Gilman Drive,

San Diego, CA 92093-0202, USA

R. C. Boland

NOAA Fisheries, Pacific Islands Fisheries Science Center, 2570 Dole Street,

Honolulu, HI 96822-2396, USA

A. M. Friedlander

US Geological Survey,

Hawaii Cooperative Fishery Research Unit

and Department of Zoology,

University of Hawaii at Manoa,

2538 McCarthy Mall, 152 Edmundson Hall,

Honolulu, HI 96822-2279, USA northwestern end of the Hawaiian Islands, an archipelago in which east-northeasterly trade winds dominate onshore water flow and transport by surface currents. The densities of recruits (juveniles $\leq 5 \mathrm{~cm}$ total length) were higher overall on windward versus leeward sectors of carbonate rock-rubble back reefs at both atolls, and the pattern was stronger for smaller (likely younger, more recently settled) recruits of four of the five most abundant species and the remainder pooled as an "Other" taxon. The windward-leeward disparity was four-fold greater at Pearl Hermes (the atoll with a three-fold longer perimeter) than at Kure. Resident predator biomass also was correlated with recruit densities, but habitat (benthic substratum) effects were generally weak. The distribution and abundance of recruits and juveniles of the primarily endemic reef fishes on shallow back reefs at these atolls appear partly influenced by relative rates of water flow over windward vs. leeward sectors of barrier reef and by the size, shape, and orientation of habitat parcels that filter out postlarval fishes with relatively weak swimming capabilities like labroids. Whole-reef geomorphology as well as fine-scale habitat heterogeneity and rugosity should be considered among the suite of many factors used to interpret observed spatial patterns of post-settlement juvenile fish distribution at atolls and perhaps some other tropical reefs.

Keywords Reef fish recruitment · Labroids · Larval dispersal - Wind transport · Post-settlement factors . Habitat selection · Piscivory 


\section{Introduction}

The mostly uninhabited low islands of the Northwestern Hawaiian Islands (NWHI) comprise an extensive series of reefs, banks and atolls that represent the most northern and western two-thirds of the 2,000-km-long Hawaiian Archipelago. Three atolls (Kure, Midway, and Pearl and Hermes), separated by 100 - to $150-\mathrm{km}$ from their nearest neighbor, are situated at the extreme northwestern end of the NWHI (Fig. 1). All three are classic atolls, with fore reef separated from back reef and patch reefs, the latter within a semi-enclosed lagoon having at least one major pass. The three atolls are either located at (Kure) or near the "Darwin Point" (Grigg 1982) at which coral accretion is balanced by erosion and subsidence. Coral cover is sparse and substratum is dominated by carbonate rock, carbonate rubble (especially on back reefs within lagoons), and macroalgae (Vroom et al. 2006). Habitat structure is relatively simple compared to coral species-rich equatorial reefs in the Indo-Pacific (Vroom et al. 2006).

Fish faunas of the far NWHI atolls are dominated by labroids (labrids, scarids) and allied pomacentrids (DeMartini 2004), many species of which are endemic (DeMartini and Friedlander 2004). Their recruits settle onto reefs from the water column after relatively brief (several weeks in pomacentrids to several months in labroids) pelagic larval durations as small (typically 1- to 2-cm total length; Victor 1987) and morphologically unspecialized post-larvae with swim-

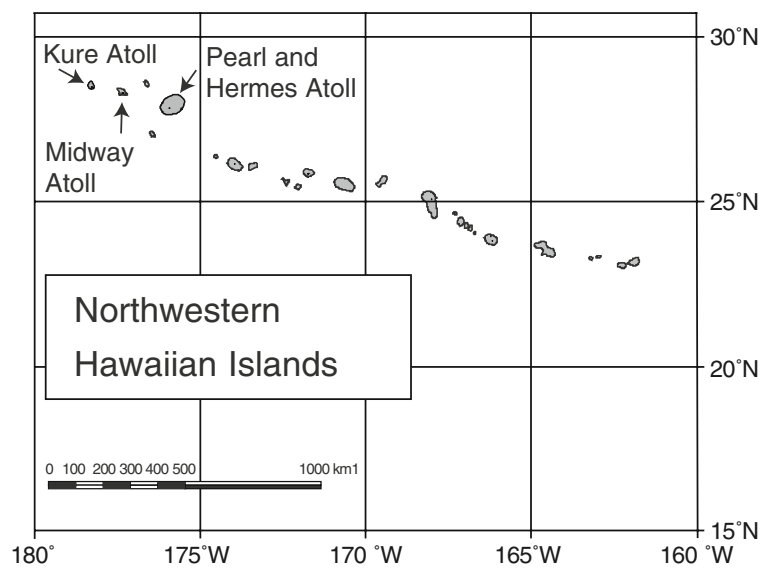

Fig. 1 Map of the Northwestern Hawaiian Islands showing major islands, reefs, and atolls. Kure (KUR), Midway, and Pearl and Hermes (PHR) Atolls are indicated by arrows ming capabilities that are weak relative to other, larger and morphologically specialized taxa like acanthurids and chaetodontids (Leis and McCormick 2002). Hawaiian endemics in general are weak dispersers that exhibit significant genetic metapopulation structure (Eble et al. 2009).

Wave-sheltered back reefs and patch reefs are prime recruitment and nursery habitats at these NWHI atolls (DeMartini 2004). The densities of adult labroids and most other reef fishes are generally greater on atoll fore reefs than inside their lagoons (DeMartini et al. 2002); and it is likely that most spawning activity occurs on the fore reef (and in passes) and that larger pools of competent (ready-tosettle) post-larvae occur in fore reef waters outside of these atolls, as at most atolls elsewhere (Leis 1994). Most larvae recruiting to back reefs and patch reefs within these atoll lagoons must be entering the lagoons over the barrier reef, and environmental factors influencing the occurrence and intensity of this transport must importantly effect the spatial distributions of recruits.

Peak settlement occurs episodically during the summer for reef fishes throughout the Hawaiian Archipelago (Walsh 1987; DeMartini and Friedlander 2004). Summer is when northwesterly swells generated by North Pacific storms are least frequent and smallest in Hawaii and nearshore reefs are then least turbulent (Friedlander et al. 2005) and provide the most wave-sheltered environments for juvenile reef fishes. East-northeasterly trade winds that blow from northeast to southwest dominate Ekman flow during the summer in Hawaii (Firing and Brainard 2006). All of the mostly small-bodied (DeMartini and Friedlander 2004), endemic fishes of Hawaii are site-attached as benthic juveniles and adults and have small home ranges (Ross 1986; DeMartini 1998); hence, most dispersal is by planktonic eggs and pelagic larvae-juveniles.

In this study we describe the influences of windwave exposure on the distribution and abundance of newly recruited reef fishes. Patterns are described using in situ diver-surveys conducted over several weeks of a summertime period in windward and leeward sectors of shallow back reefs at Kure and Pearl and Hermes atolls. Prior surveys at Kure had suggested that recruit fish abundances are greater on windward vs. leeward sectors of the back reef in late summer (Walsh et al. 2002). The specific predictions 
we tested in our study were: (1) recruit densities should be higher on sheltered back reefs adjacent to wind-wave "exposed" (windward) sectors of the atolls experiencing greater water transport; (2) such patterns should be magnified for smaller, younger recruits that have settled more recently; and (3) we should observe prior detected patterns again at Kure and, if spatially general, these should be further observable at Pearl and Hermes. In conclusion, implications of the observed spatial patterns are discussed in terms of dispersal among reef fish metapopulations in the NWHI and throughout the Hawaiian Archipelago.

\section{Materials and methods}

\section{Study area}

Surveys of fishes and habitats were conducted using SCUBA in $1-5 \mathrm{~m}$ depths along back reefs at Kure (KUR; $28.42^{\circ} \mathrm{N}, 178.33^{\circ} \mathrm{W}$ ) and Pearl and Hermes (PHR; $27.83^{\circ} \mathrm{N}, 175.83^{\circ} \mathrm{W}$ ) atolls. Oceanic waters flow into and exit the lagoons of these atolls through passes, although most water flows into the lagoons of these NWHI atolls, and many other atolls and reefs elsewhere (Callaghan et al. 2006; Coronado et al. 2007), across their barrier reefs (R. Hoeke, NOAA Fisheries, Pac. Islands Fish. Sci. Center, personal communication). The major difference between KUR and PHR is size: KUR has a diameter of $10 \mathrm{~km}$ whereas the major (northeast to southwest) and minor axes of PHR are 32 and $20 \mathrm{~km}$, respectively. The two atolls thus differ somewhat in shape: KUR is roughly circular while PHR is more elliptical in outline. Stations (surveyed sites) spanned the entire back reef perimeter at each atoll-distances of 23 and $65 \mathrm{~km}$, respectively (Fig. 2). Surveys at KUR were conducted at 30 stations during a 5-d period from 24 to 28 July 2007, and at PHR at 58 stations during 11 days from 29 July to 8 August 2007.

\section{Survey protocols}

Densities of predators on recruits and the availabilities of corals and other habitats (two post-settlement factors that might confound the effects of presettlement transport and recruit settlement) were concurrently assessed with recruit densities. Surveys consisted of standard 45-min dives. At each station, 2, 50-m long strip (belt) transects were surveyed; each of two divers (BJZ, RCB) surveyed one of the two transects, set parallel to each other along 1- to 3-m deep isobaths. Divers operated at least 5-m apart (lateral underwater visibility always exceeded $5 \mathrm{~m}$ and averaged $10 \mathrm{~m}$ ) and alternated between reef crest and lagoon sides of the back reef to distribute possible observer biases and microhabitat variations in species composition and abundance equally between divers. At each station, each diver first counted the numbers of fish predators of recruits encountered along a 50-m long $\times 4-\mathrm{m}$ wide strip $\left(200-\mathrm{m}^{2}\right.$ area) as the transect line was laid and then swam back along the laid line, recording the numbers of recruit fishes encountered within a $50-\mathrm{m}$ long $\times 2-\mathrm{m}$ wide strip $\left(100 \mathrm{~m}^{2}\right)$. Larger juvenile and adult $(\geq 10$-cm TL) predators were tallied by species and 5 -cm length-class. Recruits $(\leq 5-\mathrm{cm}$ TL, including those of predators) were tallied by lowest recognizable taxon or species (Randall 2007) and 1-cm TL length-class. Predators of recruits were defined as all moderate-sized $(10-40 \mathrm{~cm})$ reef fishes either known (e.g., see Parrish et al. 1986) or morphologically capable of consuming $1-5 \mathrm{~cm}$ long fishes.

To assess benthic habitat, the percentage cover of major coral taxa and other predominant types of substrata were described using a line point intercept (LPI) method (Nadon and Stirling 2007). Intercept points were equally spaced at $50-\mathrm{cm}$ intervals $(100$ points per $50-\mathrm{m}$ line, 200 total points per station). Live corals were recorded by genus-species or major growth form. Growth forms ranged in structural complexity from prostrate (lobe coral Porites lobata, Montipora spp., Leptastrea spp.) to discrete and branched like Pocillopora spp. Digitate corals (e.g., finger coral Porites compressa) were rare. Discretebranching and digitate growth forms were postclassified as "rugose" and prostrate corals as "nonrugose"; taxa were pooled for analyses within coral growth form. Erect fleshy algae (macroalgae $>1-\mathrm{cm}$ tall), consolidated carbonate rock (dead coral) with short $(<1-\mathrm{cm}$ high) turf algae, unconsolidated (easily moveable by hand), carbonate rubble $(>1 \mathrm{~cm}$ particle diameter), and sand $(<1 \mathrm{~cm}$ diameter $)$ were the other recorded substratum types. Percentage cover of each of these six substrata was estimated at each station based on the 200 total points. Prior to the surveys described herein, EED conducted a test comparing 
Fig. 2 Chart of a Kure and b Pearl and Hermes Atolls, Northwestern Hawaiian Islands, showing survey locations. Stations are labeled by wind-wave exposure $(\mathrm{W}=$ windward, $\mathrm{L}=$ Leeward). Numerical densities $\left(\mathrm{N} \cdot 100 \mathrm{~m}^{-2}\right)$ of total recruit fishes $(\leq 5 \mathrm{~cm}$ total length, TL) are indicated by pie diagram opposite each location. Each recruit pie diagram is partitioned into SMALL $(\leq 2 \mathrm{~cm}$ TL) and LARGE (3-5 cm TL) size-classes separately for saddle wrasse Thalassoma duperrey and a compound "All Remaining" recruit taxon excluding saddle wrasse. Locations of passes are indicated by arrows. Note different scales in (a) and (b)
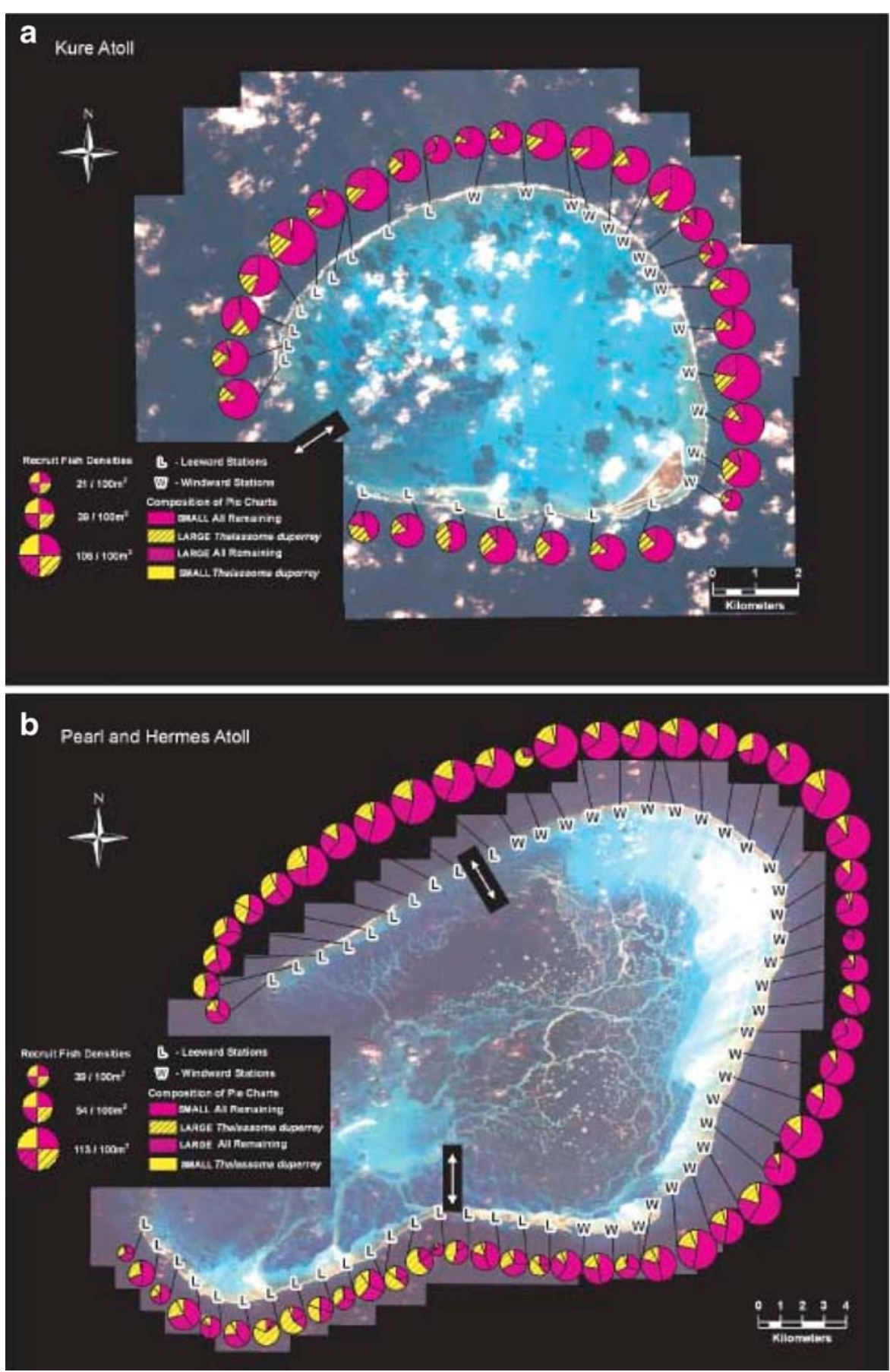

substrate percent cover estimates between matched plot (multiple $1-\mathrm{m}^{2}$ quadrats) and plotless LPI methods on $50-\mathrm{m}$ transects at several reefs in the main Hawaiian Islands that provided a broad range of substrate types and coral morphologies. Mean percent cover estimates were indistinguishable between methods
( $t$-tests: all $P>0.2$ ) and the LPI method was unbiased (least squares regression of plot on plotless methods: slopes =0.82-1.06; all $P>0.01 \mathrm{~ns}$ - see "Statistical Analysis") for all major substratum categories.

The initial station surveyed at each atoll was located randomly. Subsequent stations were spaced 
approximately 0.5 (KUR) and $0.7 \mathrm{~km}$ (PHR) apart so as to extend the survey area along the entire back reef perimeter of the respective atoll. Stations were sited haphazardly based on minimal criteria $(>50 \%$ reef substrata and a constant depth $\pm 1 \mathrm{~m}$ for the entire transect). Global Positioning System positions of stations were plotted on charts and classified (before any biological data were analyzed) as either "windward" or "leeward" exposure depending on whether the station position fell into one of two, roughly equal-sized sectors falling on either side of an imaginary northwest-southeast line bisecting the respective atoll.

\section{Statistical analysis}

Conventional parametric and nonparametric tests (Sokal and Rohlf 1981; Siegel and Castellan 1988) were used to compare habitat characteristics and recruit density patterns between wind-wave exposures and atolls and to relate densities between size-stages of recruits and between recruits and larger juvenilesadults at individual stations. Choice of the specific test was based on characteristics of the particular metric and its case-specific sampling distribution. Predator biomass density and a habitat index were used as covariates in analysis of covariance (ANCOVA) to statistically control for possible predation and habitat effects that might obscure transport influences of recruit distribution and abundance. Predator biomass was estimated by multiplying size class-specific counts and weights derived using length-weight relations (FishBase). The covariate chosen to index habitat was the simple difference between the two most important substrate types (carbonate rock/rubble and erect fleshy algae) identified by principal component analysis (PCA) of substrate composition (proc PRINCOMP; SAS Institute Inc. 2004). Variance heterogeneity was evaluated using Cochran's C test (Underwood 1997). Parametric analyses were used only after variances of density and substratum percent cover estimates had been made homogeneous after log- and arcsine-square roottransformation, respectively. The Bonferroni correction $\left(P_{\text {crit }}=100 \alpha / m \%\right)$, where $m=$ number of comparisons; Manly 1991) was used to adjust pvalues wherever multiple testing was unavoidable. Interaction effects in analysis of variance (ANOVA) and ANCOVA are not listed if insignificant.

\section{Results}

Habitat characteristics

Percentage live coral cover was low, with a mean of $6.8 \%(\mathrm{SE} \pm 0.9)$, and equivalent at the two atolls and for windward and leeward exposures (2-way ANOVA - atoll effect: $F_{1,84}=0.3, P=0.57$; exposure effect: $\left.F_{1,84}=0.1, P=0.80\right)$. Rugose coral cover represented one-third to one-half of all live coral. Rugose coral cover differed between atolls at the back reef scale (2-way ANOVA-atoll: $F_{1,84}=4.8, P=0.03$ ) but the magnitude of this difference was trivial $(<2 \%$ greater cover; $3.8 \%$ at KUR vs. $2.1 \%$ at PHR). Carbonate rock with a mean of $36 \%(\mathrm{SE} \pm 2)$ and fleshy macroalgae at $32 \%(\mathrm{SE} \pm 2)$ co-dominated benthic cover and did not differ between exposure sectors or atolls $(P=0.21-0.55)$. Rubble constituted most of the remainder at $15 \%(\mathrm{SE} \pm 1)$. Sand at $9 \%$ $(\mathrm{SE} \pm 1)$ was the only substratum other than rugose coral that appeared to differ spatially. Sand cover was nominally $1 \%$ greater in the windward sector at PHR ( $8 \%$; 2-way ANOVA-exposure: $F_{1,84}=4.2, P=$ $0.04 \mathrm{~ns})$. However, unlike rugose coral, sand did not differ overall between atolls (2-way ANOVA-atoll: $F_{1,84}=0.2, P=0.69$ ).

Benthic habitats of windward and leeward exposures at the two atolls could be succinctly characterized by the first two principal components in PCA. Carbonate substrata (rock plus rubble) and erect fleshy algae, the substrata that together represented $82-87 \%$ of all benthic cover, were negatively correlated with one another and dominated both $\mathrm{PC} 1$ and PC2. The first two principal components together explained from 92 to $97 \%$ of total habitat variance for the four atoll-exposure combinations.

\section{Densities of larger juvenile-adult predators}

More than $98 \%$ (by number) of all larger ( $\geq 10 \mathrm{~cm} \mathrm{TL}$ ) predatory fishes observed were resident species as defined by DeMartini et al. (2005). Relatively largebodied, transient piscivores were rare but dominated overall predator biomass. Transient piscivores were excluded from all following analyses because they inordinately influenced the precision of predator biomass estimates and because recruit-sized fishes do not contribute appreciably to the diet of large carangids that dominate transient piscivore biomass in 
the NWHI (DeMartini et al. 2005). All resident and transient predatory fishes that were encountered are listed in Appendix A of the Electronic Supplementary Material.

Most resident predators were wrasses (labrids), and these were dominated (in numbers: $60 \%$, biomass: $27 \%$ ) by the ubiquitous saddle wrasse Thalassoma duperrey, one of the most abundantly recruiting species. The old woman wrasse Thalassoma ballieui ranked second highest in biomass among resident predators $(22-24 \%$ at the two atolls). Saddle wrasse and one other labrid - the elegant coris (Coris venusta) - were the only resident predators whose recruits contributed nontrivially to total recruit counts at the time of our surveys. These two "recruiting" species represented about two-thirds of all resident predators by number $(6.0 \pm 0.3$ [SE] individuals. $100 \mathrm{~m}^{-2}$ ) and one-third of all resident predator biomass. Cannibalism might obscure positive numerical population responses between recruits and larger juvenile and adult conspecifics; hence, resident predator biomass was partitioned into the two recruiting species and a complementary "non-recruiting" taxon of all other resident predator taxa. The biomass of recruiting predators was $60 \%$ greater at KUR vs. PHR (187 vs. $117 \mathrm{~g} \cdot 100 \mathrm{~m}^{-2}$; 2-way ANOVA-atoll: $\left.F_{1,84}=7.2, P<0.009\right)$ but was unaffected by exposure (2-way ANOVA - exposure: $P=0.68$ ). Non-recruiting predator biomass did not differ between atolls or between exposures (2-way ANOVA-atoll: $P=0.18$; exposure: $P=0.15$ ). Correlations between biomass of non-recruiting predators and numbers of recruits were positive at each atoll for SMALL recruits $(1-2 \mathrm{~cm}$ TL, likely younger-more recently settled) but not LARGE recruits $(3-5 \mathrm{~cm}$ TL, likely older-less recently settled), and significantly so for SMALL recruits at $\operatorname{KUR}\left(r_{s}=0.37, P=0.04\right.$, Fig. 3$)$.

Species composition and densities of recruit fishes

Five species of Hawaiian endemics (four labrids, one scarid; Fig. 4) consistently represented $>90 \%$ of all recruit fishes encountered within exposure sectors at the atolls, with a single species, the belted wrasse Stethojulis balteata, contributing $60 \%$ to total recruit numbers (Fig. 5). An "Other" taxon of remaining species (excluding the Top 5 species) made up $4.3 \%$ and $5.7 \%$ of the remaining recruits tallied at KUR and PHR, respectively (Figs. 5a, b). A grand total of 31

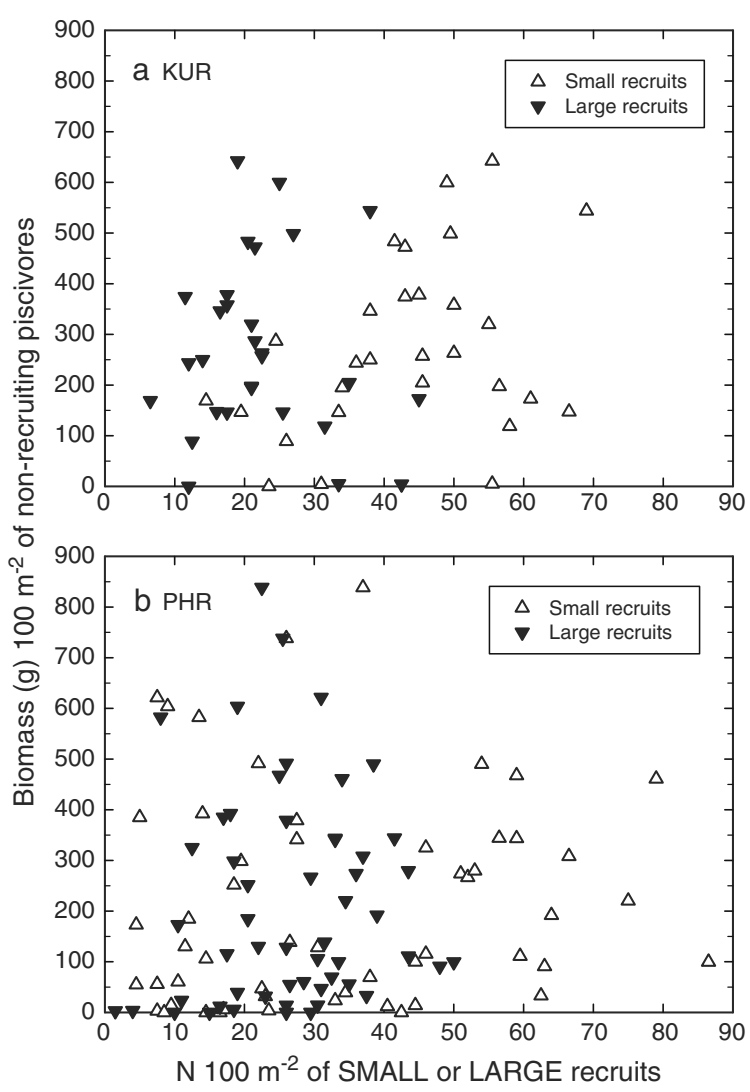

Fig. 3 Scatterplot of correlations between the biomass densities of larger juveniles-adults $(\geq 10 \mathrm{~cm} \mathrm{TL})$ of non-recruiting species of resident predators and the numerical densities of SMALL $(\leq 2 \mathrm{~cm} \mathrm{TL})$ and LARGE $(3-5 \mathrm{~cm} \mathrm{TL})$ recruits of all taxa at a KUR and b PHR. Non-recruiting resident predators exclude two species of wrasses (saddle and elegant coris) well represented in the recruit counts $(22 \%$ and $5 \%$ of all recruits, respectively). (See Appendix A in Electronic Supplemental Material for list of all predator species)

species of recruits were surveyed (Appendix B in Electronic Supplementary Material), with 11 additional species encountered at PHR (27 species total), the more extensively surveyed atoll, vs. KUR (19 species total, with only 3 unique to KUR).

Wind-wave exposure pervasively influenced recruit densities but effects differed among species and somewhat between the two atolls (Table 1). Although relations with exposure were generally similar for both SMALL and LARGE recruits of respective taxa, patterns were stronger for SMALL recruits and this paper hereafter focuses on the SMALL size-class (Table 1). The densities of SMALL recruits were everywhere similar except for leeward PHR, where they were relatively low for each of four of the Top 5 
Fig. 4 Photographs of the top-ranked species of recruit fishes in surveys: a belted wrasse Stethojulis balteata, b saddle wrasse Thalassoma duperrey, c Hawaiian gregory damselfish Stegastes marginatus (representing $35 \%$ of the Other taxon), d snubnose wrasse Macropharyngodon geoffroy, e elegant coris wrasse Coris venusta, and $\mathbf{f}$ regal parrotfish Scarus dubius. Photo credits_-J. Johnson: a,c; EED: b,d,e; J. Leung: f, layout, and formatting for final production
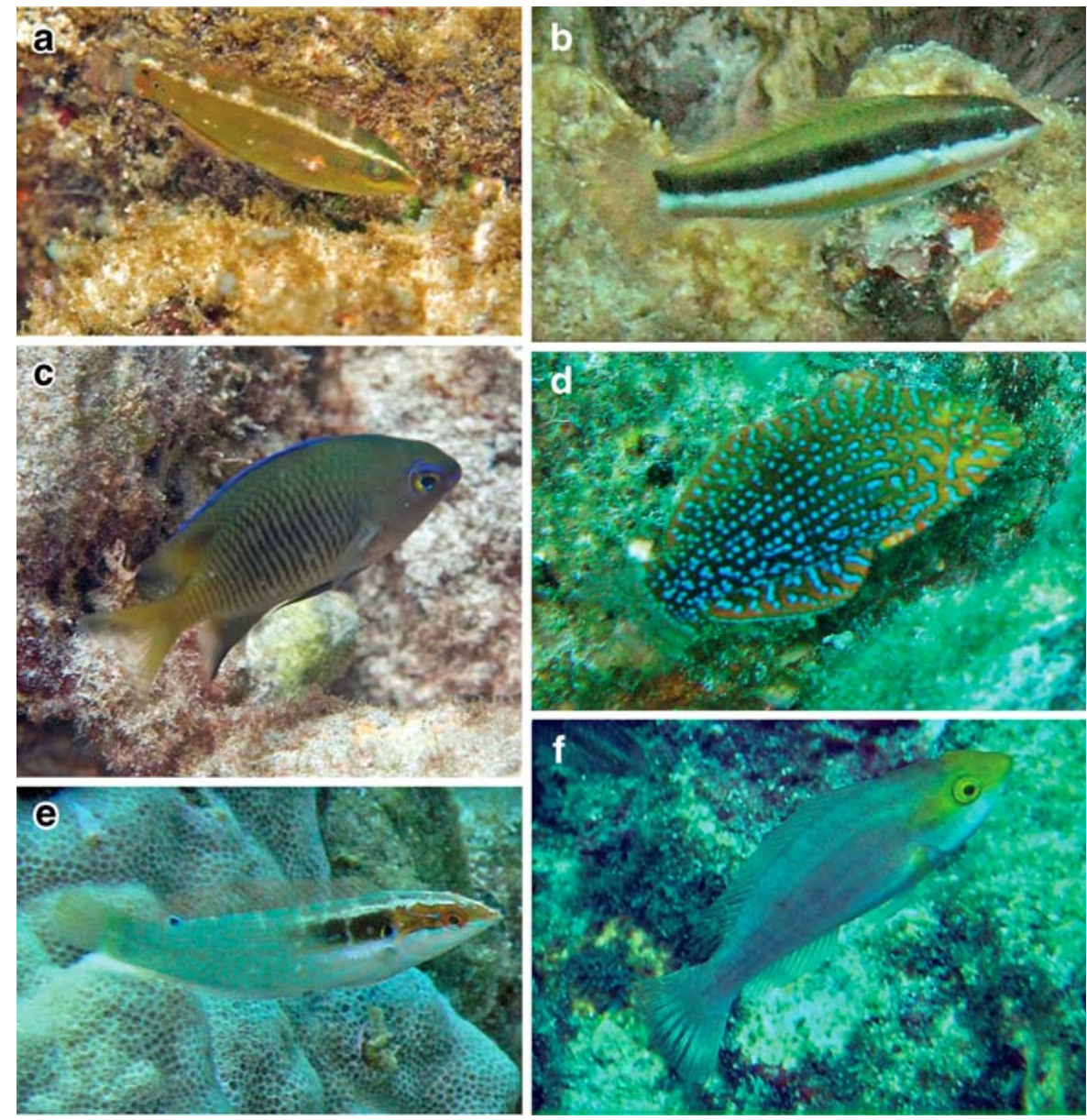

species plus the 3rd ranked Other taxon (Table 1). The endemic Hawaiian gregory (Stegastes marginatus) contributed $74 \%$ and $30 \%$ to SMALL Other recruits at KUR and PHR, respectively, and was more than one-third less abundant at leeward vs windward PHR. Twelve of the fifteen species of SMALL Other recruits at PHR were less abundant in leeward vs. windward sectors (Wilcoxon matched-pairs signedranks test; $T=19,0.025>P>0.01$ ). As a result of lower densities at leeward PHR, recruit densities tended to be higher overall at KUR vs. PHR (Table 1). The exception was saddle wrasse, the 2nd-ranked recruit species, whose densities were higher at PHR and trended greater leeward (Table 1).

Predator biomass and habitat covariates variably influenced the effects of exposure and atoll on recruit densities, depending on species and taxon, but nowhere did they overshadow the primary effects of exposure and atoll (Table 1). The biomass of nonrecruiting resident predators tended to be more influential than habitat represented by the carbonate rock/rubble-algae difference. The correlations were positive wherever recruit densities were significantly or suggestively correlated with the biomass of nonrecruiting resident predators (Table 1). The two covariates were themselves correlated: predator biomass was positively related to the carbonate rock/ rubble-algae difference (Spearman's rank correlation: $r_{s}=+0.32$ and $P=0.09, r_{s}=+0.56$ and $P<0.0001$, $r_{s}=+0.50$ and $P<0.0001$ for KUR, PHR, and both atolls pooled, respectively). Interactions between covariates (Table 1) reflect the greater strength of the correlation at PHR vs. KUR.

\section{Correlations between conspecific life-stages}

Most observed relations between the densities of SMALL and LARGE recruits matched by station were positive, and many significantly so (Table 2). Correlations between the densities of recruits and 


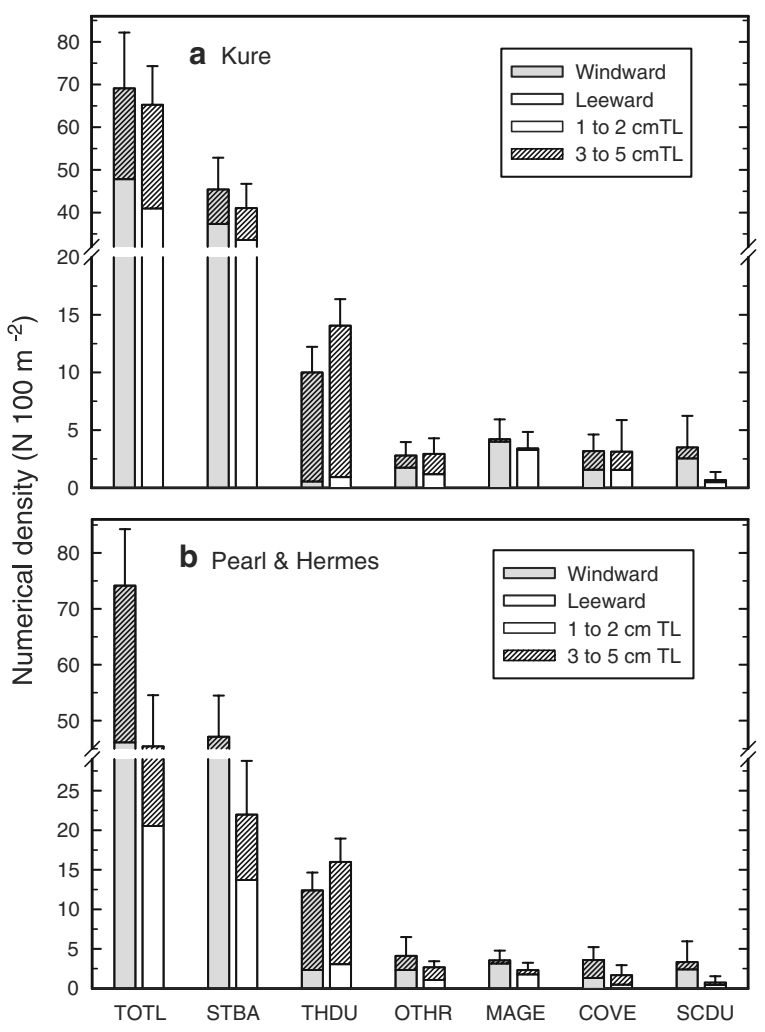

Fig. 5 Bar histograms depicting the densities of total recruits surveyed and of each of the Top 5 species plus the compound Other taxon, between windward and leeward exposure sectors at a Kure and b Pearl and Hermes Atolls. The Top 5 species and Other taxon are ranked based on overall numerical density at both atolls and ordered from left to right by descending density and labeled by scientific name acronym (STBA: belted wrasse; THDU: saddle wrasse; Other; MAGE: snubnose wrasse; COVE: elegant coris wrasse; SCDU: regal parrotfish). See Fig. 4 caption for scientific names. Bar designations are partitioned into SMALL $(\leq 2 \mathrm{~cm}$ TL; hollow) and LARGE (3-5 cm TL; diagonal lines) recruits. Vertical lines indicate +2 $\mathrm{SE}$ of the mean density of recruits of all sizes

larger juvenile-adult conspecifics also were positive and significant for saddle wrasse and elegant coris, the two resident predators that were nontrivially represented in the recruit counts (Table 2). The overall spatial correlation between the densities of SMALL and LARGE recruits was positive at each atoll (KUR: $r_{s}=+0.47, P<0.01$; PHR: $r_{s}=+0.59, P<0.0001$; Fig. 6).

\section{Discussion}

Wind-wave exposure appears to have had a pervasive influence on recruit distributions and densities in our study. However, several other key issues (influences of habitat and predators, correlations between the densities of recruits and older juvenile and adult conspecifics) must first be considered to put interpretations of wind-wave exposure in proper context.

Influences of benthic habitat and predators

Habitat composition and distribution likely did not strongly influence the distribution and abundance of recruits at KUR and PHR back reefs because substrate composition was similar throughout exposure sectors at both atolls. Carbonate rock and algae predominated regardless of exposure or atoll. Rugose substrata like corals (DeMartini and Anderson 2007) contributed little to overall benthic cover at both atoll back reefs.

That the few observed correlations between habitat and fish density involved resident predators rather than recruits suggests that spatial variations in carbonate rock/rubble and algae were influencing the distributions of secondary predators more so than their prey. Resident predators as well as herbivores are the prey of apex predators like transient carangids (DeMartini et al. 2005), and habitat features also provide shelter from predation for larger-bodied prey.

Predator density was correlated with recruit distribution and density for some recruit and predator taxa. The positive correlations between the densities of recruits and non-recruiting predators suggest either that predators were concentrating at places where prey were abundant (Connell 1996) or that numerical population responses were lagged over years of poor recruitment for some species (see below). Correlations between recruits and predators also were positive for species of predators that were recruiting (saddle wrasse and elegant coris), introducing the possibility that the correlations for recruiting species might represent more than just predator attraction.

\section{Within-species relationships}

The generally positive correlations between the densities of SMALL and LARGE recruits and between SMALL recruits and larger juvenile and adult conspecifics might represent lagged numerical responses by juvenile-adult segments of populations resulting from localized concentrations of recruits (Adams and Ebersole 2004). The first author has never observed agonistic behaviors among recruits or 
Table 1 ANCOVA results of the effects of wind-wave exposure (W = windward, $\mathrm{L}=$ leeward $)$ and atoll $(\mathrm{KUR}=$ Kure, $\mathrm{PHR}=$ Pearl and Hermes), on the numerical densities of the SMALL sizeclass of each of the a.-f. Top 5 ranked species plus the compound Other taxon and g. their aggregate excluding saddle wrasse. The two covariates evaluated are "non-recruiting" predator biomass and a habitat metric of the simple difference between the arcsine-square root-transformed proportion cover of carbonate rock/rubble and erect fleshy algae. Densities were $\log (\mathrm{x}+1)$-transformed prior to analyses. Covariates and higher-order terms are retained in final model and specified only if significant after penultimate model run $(P<0.05 / m=<0.05 / 6 \simeq<0.01)$. Relative magnitude of least square means (back-calculated to original scale) are indicated for a posteriori contrasts

\begin{tabular}{|c|c|c|c|c|}
\hline Factor & df & MS & $F$ & Prob $>F$ \\
\hline \multicolumn{5}{|l|}{ SMALL belted wrasse (Model: $F_{3,83}=20.5, P<0.0001, r^{2}=0.43$ ) ${ }^{\mathrm{a}}$} \\
\hline Atoll & 1 & 1.85 & 21.1 & $<0.0001$ \\
\hline Exposure & 1 & 1.47 & 16.8 & $<0.0001$ \\
\hline Atoll $\times$ exposure & 1 & 1.03 & 11.7 & 0.001 \\
\hline Residual & 83 & 0.88 & & \\
\hline \multicolumn{5}{|l|}{ SMALL saddle wrasse (Model: $\left.F_{2,84}=14.9, P<0.001, r^{2}=0.26\right)^{\mathrm{b}}$} \\
\hline Atoll & 1 & 15.46 & 25.7 & $<0.0001$ \\
\hline Exposure & 1 & 3.03 & 5.0 & $0.028 \mathrm{~ns}$ \\
\hline Residual & 84 & 0.60 & & \\
\hline \multicolumn{5}{|l|}{ SMALL Other taxon (Model: $F_{3,83}=12.8, P<0.0001, r^{2}=0.32$ ) ${ }^{\mathrm{c}, \mathrm{d}, \mathrm{e}}$} \\
\hline Habitat covariate & 1 & 1.09 & 2.4 & 0.12 \\
\hline Predator biomass covariate & 1 & 7.54 & 16.6 & 0.0001 \\
\hline Exposure & 1 & 2.11 & 4.7 & $0.034 \mathrm{~ns}$ \\
\hline Residual & 83 & 0.45 & & \\
\hline \multicolumn{5}{|l|}{ SMALL snubnose wrasse (Model: $\left.F_{2,84}=6.0, P<0.004, r^{2}=0.12\right)^{\mathrm{f}, \mathrm{g}}$} \\
\hline Habitat covariate $\times$ predator biomass covariate interaction & 1 & 6.02 & 7.1 & $0.01 \mathrm{~ns}$ \\
\hline Atoll & 1 & 5.01 & 5.9 & $0.017 \mathrm{~ns}$ \\
\hline Residual & 84 & 0.85 & & \\
\hline \multicolumn{5}{|c|}{ SMALL elegant coris wrasse (Model: $F_{3,83}=12.7, P<0.0001, r^{2}=0.32$ ) } \\
\hline Habitat covariate $\times$ predator biomass covariate interaction & 1 & 24.02 & 25.8 & $<0.0001$ \\
\hline Atoll & 1 & 4.19 & 4.5 & $0.037 \mathrm{~ns}$ \\
\hline Exposure & 1 & 4.14 & 4.4 & $0.038 \mathrm{~ns}$ \\
\hline Residual & 83 & 0.93 & & \\
\hline \multicolumn{5}{|l|}{ SMALL regal parrotfish (Model: $\left.F_{1,85}=12.9, P<0.002, r^{2}=0.11\right)^{\mathrm{j}}$} \\
\hline Exposure & 1 & 12.94 & 10.3 & $<0.002$ \\
\hline Residual & 85 & 1.25 & & \\
\hline \multicolumn{5}{|c|}{ SMALL Total Recruits less saddle wrasse (Model: $F_{4,82}=17.7, P<0.0001, r^{2}=0.46$ ) } \\
\hline Predator biomass covariate & 1 & 0.26 & 3.9 & $0.052 \mathrm{~ns}$ \\
\hline Atoll & 1 & 1.16 & 17.2 & $<.0 .0001$ \\
\hline Exposure & 1 & 1.19 & 17.6 & $<0.0001$ \\
\hline Atoll $\times$ Exposure & 1 & 0.87 & 12.8 & $<0.0006$ \\
\hline Residual & 82 & 0.07 & & \\
\hline
\end{tabular}

${ }^{\text {a }}$ a posteriori contrasts: KUR $>$ PHR $(+103 \%) \mathrm{W}>\mathrm{L}(+88 \%)$

${ }^{\mathrm{b}}$ a posteriori contrasts: $\mathrm{PHR}>\mathrm{KUR}(+708 \%) \mathrm{L} \geq \mathrm{W}(+140 \%)$

${ }^{\mathrm{c}} \mathrm{LSQR}$ regression: recruit density on habitat metric: $r=+0.31, P<0.003$

${ }^{\mathrm{d}}$ LSQR regression: recruit density on predator biomass: $r=+0.94, P<0.0001$

e a posteriori contrast: $\mathrm{W} \geq \mathrm{L}(+113 \%)$

${ }^{\mathrm{f}} \mathrm{LSQR}$ regression: recruit density on covariates interaction: $r=+0.06, P=0.02$

$\mathrm{g}$ a posteriori contrast: KUR $\geq$ PHR $(+125 \%)$

${ }^{\mathrm{h}}$ LSQR regression: recruit density on covariates interaction: $r=+0.24, P<0.0001$

${ }^{\mathrm{i}}$ a posteriori contrasts: KUR $\geq$ PHR $(+122 \%) \mathrm{W} \geq \mathrm{L}(+208 \%)$

${ }^{\mathrm{j}}$ a posteriori contrast: $\mathrm{W}>\mathrm{L}(+719 \%)$

${ }^{\mathrm{k}} \mathrm{LSQR}$ regression: recruit density on predator biomass: $r=+0.26, P=0.01$

${ }^{1}$ a posteriori contrasts: KUR $>$ PHR $(+76 \%) \mathrm{W}>\mathrm{L}(+57 \%)$ 
Table 2 Summary of Spearman's non-parametric rank correlations between density estimates $(\mathrm{N}$. $100 \mathrm{~m}^{-2}$ ) of a. SMALL and LARGE recruits for each of the Top 5 species of recruits, the 3rd-ranked Other compound taxon, and the aggregate of all recruits excluding saddle wrasse; and of $b$. the total recruits (both SMALL and LARGE $\leq 5 \mathrm{~cm}$ TL) and larger juveniles and adults $(\geq 10 \mathrm{~cm}$ TL) of saddle wrasse and elegant coris, two recruiting species of resident predators a. Densities of SMALL vs. LARGE recruits ( $n=87$ stations)

\begin{tabular}{lcc}
\hline Species or taxon & Spearman's $r_{s}$ statistic & Prob $\left|r_{s}\right|=0$ \\
\hline Belted wrasse & +0.53 & $<0.0001$ \\
Saddle wrasse & +0.21 & $0.05 \mathrm{~ns}$ \\
Other & +0.32 & 0.002 \\
Snubnose wrasse & +0.47 & $<0.0001$ \\
Elegant coris wrasse & +0.78 & $<0.0001$ \\
Regal parrotfish & +0.81 & $<0.0001$ \\
Total minus saddle wrasse & +0.56 & $<0.0001$ \\
b. Densities of recruits (all sizes) vs. larger juveniles and adults $(n=87$ stations $)$ & \\
Species & Spearman's $r_{s}$ statistic & Prob $\left|r_{s}\right|=0$ \\
Saddle wrasse & +0.43 & $<0.0001$ \\
Elegant coris wrasse & +0.70 & $<0.0001$ \\
\hline
\end{tabular}

between juveniles and adults of these species despite hundreds of hours of underwater observation, although this does not necessarily disprove competition that manifests as slower growth by recruits that aggregate to reduce per capita predation mortality (White and Warner 2007). Only experiments can distinguish among the several, non-mutually exclusive causes of these patterns, which include facilitated settlement, post-settlement attraction, and lagged numerical population responses within and between year-classes.

\section{Effects of wind-wave exposure}

Wind-wave exposure appears to have importantly influenced the distribution and abundance of most species of recruit fishes, and of recruit fishes overall, on back reefs at both atolls surveyed. Total SMALL recruits (excluding saddle wrasse) were 15\% (ns, but power only 0.2 ) and $60 \%$ lower density in leeward sectors at KUR and PHR, respectively, despite a $40 \%$ higher overall density of SMALL recruits of these taxa at KUR. The differences in densities at windward vs. leeward PHR for several of the Top 5 species and Other taxon were nominally large although insignificant because power was low $(0.6-0.7)$ at the species level. The pattern of lower recruit densities in the leeward sector at PHR, although spanning five families, was mostly based on labroids and pomacentrids (10 of the 12 species). The SMALL recruits of all of these high-ranked taxa except for belted wrasse were low in absolute abundance at the time of our surveys. However, these species should not be considered unimportant contributors to fish population dynamics at these atolls because each of those most abundant as recruits in the present study has been a major component of the assemblage of juvenile and adult fishes at these reefs in the recent past (Table 3).

The opposing patterns for the lone exception among the Top 5 species - saddle wrasse (suggestively higher densities in leeward sectors and a relatively

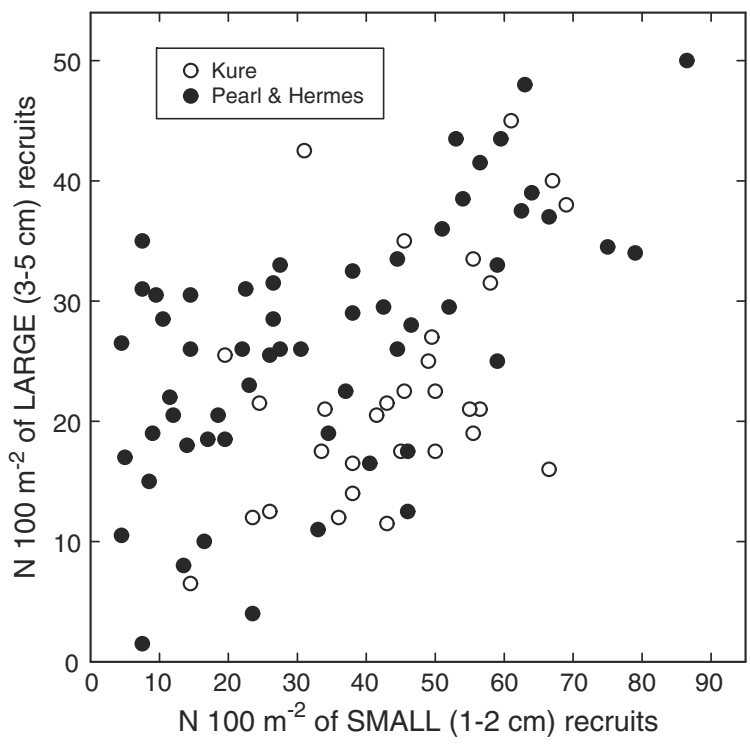

Fig. 6 Scatterplot of correlations between the numerical densities of SMALL $(\leq 2 \mathrm{~cm}$ TL) and LARGE (3-5 cm TL) recruit fishes of all taxa at KUR and PHR 
Table 3 Rank numerical densities of all (juvenile and older) fishes surveyed in 2000-02 at a. KUR and b. PHR, for each the most abundant species recorded as recruits (this study). Species are ordered by relative recruit density in this study, with Hawaiian gregory damselfish as proxy for the Other compound taxon. Fish species richness was 155 and 174 at KUR and PHR, respectively, in 2000-02. Source: Table 3 and Fig. 2 of DeMartini and Friedlander (2004)

\begin{tabular}{lcc}
\hline Species & a. KUR & b. PHR \\
\hline Belted wrasse & 5 & 16 \\
Saddle wrasse & 1 & 1 \\
Hawaiian gregory & 3 & 6 \\
Snubnose wrasse & 14 & 24 \\
Elegant coris wrasse & 19 & 28 \\
Regal parrotfish & 13 & 4 \\
\hline
\end{tabular}

weak correlation between densities of SMALL and LARGE recruits) - are perhaps related to saddle wrasse being the only species abundant both as recruits and as larger juveniles and adults when surveyed. Cannibalism by saddle wrasse (likely, based on its generalist food habits [Randall 2007] and feeding mechanism morphology) would weaken correlations between abundances of its recruit and older stages.

An apparent leeward "recruitment shadow" effect (Jones 1997) was four-fold larger-and significantly so-at PHR, the atoll with the three-fold longer perimeter. It is possible that the spatial extent of leeward back reef at KUR is too small to provide a true lee from the prevailing trade wind-generated flow of surface water currents that deliver most water over the windward barrier reef. Differences in the relative delivery rates of water over windward and leeward barrier reefs provide the most parsimonious explanation for our observed differences in recruit labroid and pomacentrid densities. Physical forcing by geostrophic flows (Cowen 2002) and wind-driven transport (Milicich et al. 1992) obviously can contribute to the settlement process and spatial distribution of recruits, despite the now generally accepted fact that reef fish larvae importantly influence their fine-scale distributions (Leis 2007). Our explanation holds regardless of the relative extents to which replenishment reflects transport from upstream reefs within 100-km distance (Cowen et al. 2006) or local reseeding (Swearer et al. 2002). Our surveys provide the first empirical evidence that the spatial distribution and abundance of recruits and the larger juveniles and adults of some species of site-attached reef fishes at atolls in the NWHI are likely influenced by the size and perhaps also shape and orientation of habitat parcels which can function as spatial filters. Our description of within-atoll patterns herein appreciably extends the information available on spatial relationships of recruit reef fishes in the NWHI, which until now was limited to general recognition of a latitudinal cline in the density of recruits (DeMartini and Friedlander 2004).

Few other empirical observations exist with which to test such a habitat filter or recruitment shadow hypothesis (Milicich et al. 1992; Booth et al. 2000). The generally recognized paradigm, largely based on theory (Lobel and Robinson 1986) and either limited empirical data (Lobel and Robinson 1988, but see Boehlert et al. 1992) or mixed oceanographic evidence (reviewed by Cowen 2002), is that downstream eddies on the leeward side of islands are where larvae typically concentrate, rather than that a windward shore might act as a filter against winddriven transport that thereby reduces the number of potential settlers on a leeward shore (Jones 1997; D'Alessandro et al. 2007). A recent study (Hamilton et al. 2006) described a case in which recently settled recruits of the bluehead wrasse Thalassoma bifasciatum were consistently concentrated at certain areas off both windward and leeward shores of St. Croix in the U.S. Virgin islands. Temporally consistent spatial patterns were attributed to a combination of habitat filtering and concentration within gyres (Hamilton et al. 2006).

The fundamentally different geomorphologies of atolls and high islands perhaps affect whether they function as filters or as gyre-inducing barriers to water flow and pelagic transport. The extent to which the windward shores of atolls act as barriers to flow and transport might depend on the development and spatial distribution of higher elevation cays on their windward barrier reefs. Because oceanic water passes over the barrier reefs of atolls to varying (from slight to major) extents, the strength of filtering likely varies among atolls of differing geomorphologies. The potential for formation of downstream eddies and gyres in general might be less at atolls than at high islands of comparable size if high islands act as greater barriers to flow than do atolls through which at least some water passes. 
In addition to reef geomorphology, many other spatial and temporal factors must importantly influence whether atolls function as filters or gyre-inducing barriers to flow and larval transport. A variety of local-scale topographic features can importantly modify advection and gyre formation at oceanic islands and coastal reefs (Wolanski and Hamner 1988; Cowen and Castro 1994). Passes at island reefs and atolls also significantly alter patterns of water flow (Wolanski and Hamner 1988). Augmented delivery rates that result from proximity to passes appear unlikely to have influenced recruit distributions in our study (Fig. 2), but stations were not positioned to test this hypothesis. Local tidal and other currents also can modify the outcome of wind-driven transport of ready-to-settle larvae (Kingsford and Choat 1986; Kingsford et al. 2005; Burgess et al. 2007). The magnitude of transport by wind-driven surface currents also can vary with seasonal changes in wind speed and direction (e.g., greater wave setup on the upwind side of reefs during trade wind periods) and can be further modified by seasonal or other temporal and spatial shifts in ocean current patterns, all of which are known to occur in Hawaiian waters (Kobashi and Kawamura 2002; Firing and Brainard 2006). Finally, in an expansive, isolated location like the Hawaiian Islands, the significance of exposure regimes might differ between islands and atolls at the "upstream" vs. "downstream" ends of the archipelago (e.g., the respective windward vs. leeward shores of the Big Island and Kure Atoll).

We caution that our study focused on potential interactions between wind-wave transport, benthic habitat composition, and predation on recruits, and our correlative data clearly cannot distinguish between the results of passive transport and active habitat selection. Other, potentially important factors include hydrography as a cue for active habitat selection by competent larvae (Fulton and Bellwood 2005). We do not imply that choice by settlers for specific flow regimes is not important (although active habitat selection should be more likely for the morphologically specialized, larger-bodied, and stronger swimming settlers of non-labroid species). We also do not imply that the re-seeding of larvae does not occur to some, perhaps appreciable, extents at these atolls. The data are, however, consistent with a greater concentration and/or delivery rate of recruits, especially SMALL individuals closer in time to settlement, at and near windward sectors of these atolls regardless of whether or not most larvae settle at the same atoll from which they have been produced. The apparent pre-settlement advection effects that we observed cannot be considered necessarily spatially pervasive or temporally consistent, despite the surveys in 2001 by Walsh et al. (2002) that prompted our study. Monitoring of recruitment over many additional years would be needed to determine whether the observed spatial differences are temporally consistent (Tolimieri et al. 1998; Sale et al. 2005). Our observations further suggest that prior settlement events carried over to influence the distribution of LARGE recruits and the larger juveniles and adults of numerous species that are site-attached and have small home ranges once resident. The data on post-settlement mortality needed to test this are lacking, badly needed, and difficult to obtain. The additional observations and experiments that are needed are prerequisite to an understanding of pelagic transport throughout the Hawaiian Archipelago and connectivity among reef-based populations in the NWHI and the MHI.

Acknowledgements We thank R. Brainard (Chief, Coral Reef Ecosystem Division, Pacific Islands Fisheries Science Center, PIFSC) and the officers and crew of the NOAA ship Oscar Elton Sette for allowing BJZ and RCB to piggyback this research on an otherwise dedicated cruise. The financial support provided to EED by the NOAA Fisheries, Coral Reef Conservation Program, Office of Habitat Conservation (OHC), is greatly appreciated. We especially thank T. Hourigan (OHC) and W.J. Walsh (State of Hawaii, Department of Land and Natural Resources) for their conceptual support of the project; R. Hoeke for information on water transport dynamics at oceanic atolls; J. Johnson and J. Leung for providing photographs; D. Yamaguchi for figure formatting; and D. Booth, D. Kobayashi, W. J. Walsh, and several anonymous reviewers for constructive comments on the manuscript.

Open Access This article is distributed under the terms of the Creative Commons Attribution Noncommercial License which permits any noncommercial use, distribution, and reproduction in any medium, provided the original author(s) and source are credited.

\section{References}

Adams AJ, Ebersole JP (2004) Processes influencing recruitment inferred from distributions of coral reef fishes. Bull Mar Sci 75:153-174

Boehlert GW, Watson W, Mundy BC (1992) Horizontal and vertical distributions of larval fishes around an isolated oceanic island in the tropical Pacific. Deep-Sea Res 39A:439-466 
Booth DJ, Kingsford MJ, Doherty PJ, Beretta GA (2000) Recruitment of damselfishes in One Tree Island Lagoon: persistent interannual spatial patterns. Mar Ecol Prog Ser 202:219-230

Burgess SC, Kingsford MJ, Black KP (2007) Influence of tidal eddies and wind on the distribution of presettlement fishes around One Tree Island, Great Barrier Reef. Mar Ecol Prog Ser 341:233-242

Callaghan DP, Nielsen P, Cartwright N, Gourlay MR, Baldock TE (2006) Atoll lagoon flushing caused by waves. Coast Eng 53:691-704

Connell SD (1996) Variations in mortality of a coral-reef fish: links with predator abundance. Mar Biol 126:347-352

Coronado C, Candela J, Iglesias-Prieto R, Sheinbaum J, Lopez M, Ocampo-Torres FJ (2007) On the circulation in the Puerto Morelos fringing reef lagoon. Coral Reefs 26:149-163

Cowen RK (2002) Larval dispersal and retention and consequences for population connectivity. In: Sale PF (ed) Coral reef fishes-dynamics and diversity in a complex ecosystem. Academic, London, pp 149-170

Cowen RK, Castro LR (1994) Relation of coral reef fish larval distributions to island-scale circulation around Barbados, West Indies. Bull Mar Sci 54:228-244

Cowen RK, Paris CB, Srinivasan A (2006) Scaling of connectivity in marine populations. Science 311:522-527

D'Alessandro E, Sponaugle S, Lee T (2007) Patterns and processes of larval fish supply to the coral reefs of the upper Florida Keys. Mar Ecol Prog Ser 331:85-100

DeMartini EE (1998) How might recruitment research on coralreef fishes help manage tropical reef fisheries? Aust J Ecol 23:305-310

DeMartini EE (2004) Habitat and endemism of recruits to shallow reef fish populations: selection criteria for no-take MPAs in the NWHI coral reef ecosystem reserve. Bull Mar Sci 74:185-205

DeMartini EE, Anderson TW (2007) Habitat associations and aggregation of recruit fishes on Hawaiian coral reefs. Bull Mar Sci 81:139-152

DeMartini EE, Friedlander AM (2004) Spatial patterns of endemism in shallow-water reef fish populations of the Northwestern Hawaiian Islands. Mar Ecol Prog Ser 271:281-296

DeMartini EE, Parrish FA, Boland RC (2002) Comprehensive evaluation of shallow reef fish populations at French Frigate Shoals and Midway Atoll, Northwestern Hawaiian Islands (1992/3, 1995-2000). NOAA Tech Memo NMFSSWFSC-347. p 54

DeMartini EE, Friedlander AM, Holzwarth SR (2005) Size at sex change in protogynous labroids, prey body size distributions, and apex predator densities at NW Hawaiian atolls. Mar Ecol Prog Ser 297:259-271

Eble JA, Toonen RJ, Bowen BW (2009) Endemism and dispersal: comparative phylogeography of three surgeonfishes across the Hawaiian Archipelago. Mar Biol 156:689-698

Firing J, Brainard RE (2006) Ten years of shipboard ADCP measurements along the Northwestern Hawaiian Islands. Atoll Res Bull 543:347-363

Friedlander AM, Aeby G, Brainard R, Clark A, DeMartini EE, Godwin S, Kenyon J, Kosaki R, Maragos M, Vroom P (2005) The state of coral reef ecosystems of the Northwestern Hawaiian Islands. In: Waddell JE (ed) The state of coral reef ecosystems of the United States and Pacific Freely Associated States. 2005. NOAA Technical Memorandum NOS NCCOS 11. NOAA/NCCOs Center for Coastal Monitoring and Assessment's Biogeography Team, Silver Spring, pp 270-311

Fulton CJ, Bellwood DR (2005) Wave-induced water motion and functional implications for coral reef fish assemblages. Limnol Oceanogr 50:255-264

Grigg RW (1982) Darwin point: a threshold for atoll formation. Coral Reefs 1:29-34

Hamilton SL, White JW, Caselle JE, Swearer SE, Warner RR (2006) Consistent long-term spatial gradients in replenishment for an island population of a coral reef fish. Mar Ecol Prog Ser 306:247-256

Jones GP (1997) Relationship between recruitment and postrecruitment processes in lagoonal populations of two coral reef fishes. J Exp Mar Biol Ecol 213:231-246

Kingsford MJ, Choat JH (1986) Influence of surface slicks on the distribution and onshore movements of small fish. Mar Biol 91:161-171

Kingsford MJ, Wolanski E, Choat JH (2005) Influence of tidally induced fronts and Langmuir circulations on distribution and movements of presettlement fishes around a coral reef. Mar Biol 109:167-180

Kobashi F, Kawamura H (2002) Seasonal variation and instability nature of the North Pacific subtropical countercurrent and the Hawaiian Lee countercurrent. J Geophys Res C 107(11):3185

Leis JM (1994) Coral Sea atoll lagoons - closed nurseries for the larvae of a few coral reef fishes. Bull Mar Sci 54:206-227

Leis JM (2007) Behavior as input for modeling dispersal of fish larvae: behaviour, biogeography, hydrodynamics, ontogeny, physiology and phylogeny meet hydrography. Mar Ecol Prog Ser 347:185-193

Leis JM, McCormick MI (2002) The biology, behavior, and ecology of the pelagic, larval stage of coral reef fishes. In: Sale PF (ed) Coral reef fishes-dynamics and diversity in a complex ecosystem. Academic, London, pp 171-199

Lobel PS, Robinson AR (1986) Transport and entrapment of fish larvae by ocean mesoscale eddies and current in Hawaiian waters. Deep-Sea Res 33(4A):483-500

Lobel PS, Robinson AR (1988) Larval fishes and zooplankton in a planktonic eddy in Hawaiian waters. J Plankton Res 10:1209-1223

Manly BFJ (1991) Randomization and Monte Carlo methods in biology. Chapman and Hall, NY

Milicich MJ, Meekan MG, Doherty PJ (1992) Larval supply: a good predictor of recruitment of three species of reef fish (Pomacentridae). Mar Ecol Prog Ser 86:153-166

Nadon M-O, Stirling G (2007) Field and simulation analyses of visual methods for sampling coral cover. Coral Reefs 25:177-185

Parrish JD, Norris JE, Callahan MW, Callahan JK, Margarifuji EJ, Schroeder RE (1986) Piscivory in a coral reef fish community. In: Simenstad CA, Cailliet GM (eds) Contemporary studies on fish feeding. Junk, Dordrecht, pp 285-297

Randall JE (2007) Reef and shore fishes of the Hawaiian Islands. University of Hawaii, Sea Grant College Program

Ross RM (1986) Social organization and mating system of the Hawaiian reef fish Thalassoma duperrey (Labridae). In: Uyeno T, Arai R, Taniuchi T, Matsuura K (eds) Indo- 
Pacific fish biology. Proc 2nd Internat Conf on Indo-Pac Fishes, Tokyo, pp 794-802, Jul 29-Aug3, 1985

Sale PF, Danilowicz BS, Doherty PJ, Williams DMcB (2005) The relation of microhabitat to variation in recruitment of young-of-year coral reef fishes. Bull Mar Sci 76:123142

SAS Institute Inc (2004) SAS/STAT ${ }^{\circledR} 9.1$ user's guide. SAS Institute, Cary

Siegel S, Castellan NJ Jr (1988) Nonparametric statistics for the behavioral sciences. McGraw-Hill, NY

Sokal RR, Rohlf FJ (1981) Biometry: the principles and practice of statistics in biological research, 2nd edn. WH Freeman, San Francisco

Swearer SE, Shima JS, Hellberg ME, Thorrold SR, Jones GP, Robertson DR, Morgan SG, Selkoe KA, Ruiz GM, Warner RR (2002) Evidence of self-recruitment in demersal marine populations. Bull Mar Sci 70:S252-S271

Tolimieri N, Sale PF, Nemeth RS, Gestring KB (1998) Replenishment of populations of coral reef fishes: are spatial patterns of recruitment consistent through time? J Exp Mar Biol Ecol 230:55-71
Underwood AJ (1997) Experiments in ecology: their logical design and interpretation using analysis of variance. Cambridge Univ Press, Cambridge

Victor BC (1987) Growth, dispersal, and identification of planktonic labrid and pomacentrid reef-fish larvae in the eastern Pacific Ocean. Mar Biol 95:145-152

Vroom PS, Page KN, Kenyon JC, Brainard RE (2006) Algaedominated reefs. Am Sci 94:430-437

Walsh WJ (1987) Patterns of recruitment and spawning in Hawaiian reef fishes. Environ Biol Fish 18:257-276

Walsh W, Okano R, Nishimoto R, Carman B (2002) Northwestern Hawaiian Islands / Kure atoll assessment and monitoring program. Final Report. Results of a September 2001 research study at Kure Atoll. Hawaii State Department of Aquatic Resources, March 2002. p 60

White JW, Warner RR (2007) Behavioral and energetic costs of group membership in a coral reef fish. Oecologia (Berl) 154:423-433

Wolanski E, Hamner WM (1988) Topographically controlled fronts in the ocean and their biological influence. Science 241:177-181 